\title{
Urologic Complications after Gynaecologic and Obstetric Surgery at the Urology-Andrology Teaching Clinic of Teaching Hospital of Cotonou
}

\author{
Hounnasso Prince Pascal', Avakoudjo Josué Georges', Babadi Naméoua1, \\ Paré Abdoul Karim 1* , Ouattara Adama ${ }^{2}$, Vodounou Alexandre1, Agounkpé Michel Michael1 \\ ${ }^{1}$ Uro Andrology Clinic, Teaching Hospital Hubert Koutoucou Maga, Cotonou, Benin \\ ${ }^{2}$ Division of Urology, Teaching Hospital Souro Sanou, Bobo-Dioulasso, Burkina Faso \\ Email: ${ }^{\text {boupare@yahoo.fr }}$
}

Received 5 August 2014; revised 2 September 2014; accepted 6 October 2014

Copyright (C) 2014 by authors and Scientific Research Publishing Inc. This work is licensed under the Creative Commons Attribution International License (CC BY). http://creativecommons.org/licenses/by/4.0/

(c) (i) Open Access

\section{Abstract}

Objective: To study the epidemiology and current trend in the management of urologic complications following obstetric and gynaecologic surgeries at CUUA University hospital of Cotonou. Patients and Methods: It was a retrospective study of patients referred with urologic complications following obstetric and gynaecological surgeries. The study took place at the Teaching Clinic of Urology Andrology at CNHU of Cotonou between April 1, 2008 and March 31, 2013. Results: Fortyone patients were studied. They represented $3.5 \%$ of people hospitalized at CUUA throughout the study period. The average age was 41 years swith range of 20 and 57 years. Twenty-one (51.2\%) of them were married. Thirty patients $(73.2 \%)$ were referred from a non-academichospital, while 7 patients $(17.1 \%)$ were referred from academic hospital. Caesarean section was the primary gyneco- logical surgery in 22 cases (53.7\%) and hysterectomy in 19 cases (46.3\%). Clinically, the pre- dominant symptoms were leakage of urine throughout the vagina and obstructive anuria with or without back pain. We found 31 cases of VVF, 5 cases of bilateral ligation of the ureters, 3 cases of unilateral ligation of the ureter, 1 ureteralinjury and 1 uretero-vaginal fistula. These complications were diagnosed postoperatively in $95.1 \%$ of cases. Surgeries done included VVF repair in 31 cases $(75.6 \%)$, unilateral ureteral reimplantation in 4 cases $(9.8 \%)$, removal of ligation of the ureters in 3 cases $(7.3 \%)$, bilateral ureteral reimplantation for 2 cases $(4.9 \%)$ and end-to-end anastomosisin 1 case $(2.4 \%)$. The postoperative period was uneventful in 29 cases and we observed 7 cases of surgical site infection. The overall success rate was $87.8 \%$. Conclusion: Urological complications following gynecologic surgeries managed at the urologic department of teaching hospital of Coto- nou had an even higher incidence. Early diagnosis especially during the

${ }^{*}$ Corresponding author.

How to cite this paper: Pascal, H.P., Georges, A.J., Naméoua, B., Karim, P.A., Adama, O., Alexandre, V. and Michael, A.M. (2014) Urologic Complications after Gynaecologic and Obstetric Surgery at the Urology-Andrology Teaching Clinic of Teaching Hospital of Cotonou. Open Journal of Urology, 4, 121-125. http://dx.doi.org/10.4236/oju.2014.410021 
operative procedure would save the patients' serious complications and open surgery due to the lack of endo-urological facilities. The most important factor in prevention is good knowledge of pelvicanatomy and good knowledge of the surgical techniques of caesarean operation section and trans-abdominal hysterectomy.

\section{Keywords}

\section{Urological Complications, Gynaecological and Obstetrical Surgery, Cotonou}

\section{Introduction}

The urologic complications following gynaecological and obstetrical surgery are more frequent in the developing countries [1]. The needs to reduce maternal and neonatal mortality rate in these countries push the government to train more surgeons, many of which are young and unskilled. They often lack the knowledge of the anatomic relationship between the urinary and the genital tracts [1] [2]. This leads to an increase in number of patients referred to our services for treatment of complications following gynaecological or obstetric surgeries. Injuries to the bladder and the lower ureter are the most frequent [3]. Gynaecological surgery was responsible for $75 \%$ of iatrogenic injuries to the ureter [4]. At the same time, it has been noted that bladder injuries are 2 to 3 times more frequent than ureteral injuries [5]. The outcome depends on the nature of the injury, the severity of the injury, time at which the diagnosis was made and the overall health status the patients hold delay in charge, localization and the functionality of the kidney known ownerless [6]. The aim of this study is to review the epidemiology and the current trend in the management of urologic complications following gynaecological and obstetrical surgery at the clinic of urology and andrology of teaching hospital of Cotonou.

\section{Materials and Methods}

It is a retrospective study that took place at the academic clinic of Urology andrology of the teaching hospital of Cotonou. It covered period of 5 years, from 1 April 2008 to 31 March 2013. It was about the patients referred at the urologic department with urologic complications following gynaecological and obstetrical surgery. The studied population was 41. Data were collected from their medical medical files. The study included all women that were referred at the urologic department of teaching hospital with urologic complications following gynaecological or obstetric surgery, and had surgical treatment in this hospital. All patients presenting with non- surgical urologic complications were excluded.

Information extracted include age, profession, marital status, referral hospital, pre-operative diagnosis, primary gynaecological or obstetric surgery, type of complication, duration between complication and referral, type of treatment, and the result of the treatment.

The data was analysed using Epi Info software version 3.4.

\section{Results}

The studied population were found to be young women whose mean age was 41 years (range 20 - 57 years). Twenty-one of them are married. They account for $3.5 \%$ of all hospital admission at service during the period of study. The primary referral center of these patients was a non-teaching hospital in 30 cases (73.2\%). Table 1 shows the distribution of the patients according to the referral hospital.

Caesarean was the primary surgery in 22 cases $(53.7 \%)$ and trans-abdominal hysterectomy in 19 cases (46.3\%).

Clinically, the predominant symptoms were leakage of urine via vagina, anuria, and lumbar pain. Leakage of urine was confirmed by methylene blue dye test, ultrasounds and intravenous urography were also used to help in making diagnosis. The commonest urologic complication following gynaecological surgeries was found to be vesico-vaginal fistulas as seen in 31 cases, and ligation of ureter (s) as seen in 8 cases. Table 2 showed the distribution of patients according to the type of complication.

It is also observed that $23(74.2 \%)$ of the 31 cases of vesico-vaginal fistulas (VVF) were referred from a nonacademic public hospital while only 5 patients $(16.1 \%)$ were referred from an academic hospital. Table 3 shows the distribution of VVF according to primary referral hospital. 
Table 1. Distribution of the patients according to the sending hospital.

\begin{tabular}{ccc}
\hline Sending hospital & Frequence & Pourcentage (\%) \\
\hline Non-academic public hospital & 30 & 73.2 \\
Teaching hospital & 7 & 17.1 \\
Private hospital & 2 & 4.9 \\
No details & 2 & 4.9 \\
Total & 41 & 100 \\
\hline
\end{tabular}

Table 2. Distribution of the patients according to the type of complication.

\begin{tabular}{ccc}
\hline Type of complication & Frequence & Pourcentage (\%) \\
\hline Vesico-vaginal fistulas & 31 & 75.6 \\
Bilateral ligation of the ureters & 5 & 12.2 \\
Unilateral ligation of ureter & 3 & 7.3 \\
Wound ureter & 1 & 2.4 \\
Uretero vaginal fistula & 1 & 2.4 \\
Total & 41 & 100 \\
\hline
\end{tabular}

Table 3. VVF according to the structure of source.

\begin{tabular}{ccc}
\hline Sending hospital & Frequence & Pourcentage (\%) \\
\hline Non-academic public hospital & 23 & 74.2 \\
Teaching hospital & 5 & 16.1 \\
No details & 2 & 6.5 \\
Private hospital & 1 & 3.2 \\
Total & 31 & 100 \\
\hline
\end{tabular}

4 out of the 5 bilateral ureteric ligations were referred from non-academic public hospital.

Though most of the complications were diagnosed in the immediate postoperative period in $39(95.1 \%)$ of the cases, $19(46.3 \%)$ of the patients were referred more than a year after diagnosis. A case of ureteric injury and a case of bilateral ligation of ureters have been diagnosed during surgery. All VVF were diagnosed during the postoperative period.

Ureteric ligation following Caesarean section was noticed in 2 cases and following trans-abdominal hysterectomy in 7 cases. While VVF followed caesarean section in 20 cases $(64.5 \%)$ and trans-abdominal hysterectomy in 11 cases $(35.5 \%)$.

All the patients under went surgical treatment. This includes 31 repairs of VVF, 2 bilateral vesico ureteral reimplantation, 4 unilateral vesico ureteral reimplantation, 3 removals of ureteric ligatures, and 1 repair of uretero-vaginal fistula. Table 4 showed the distribution of patients according to the nature of treatment given.

Two of the ureteric ligations were treated within 10 postoperative days, while the remaining 39 patients $(95.1 \%)$ were treated at least 1 month after the primary surgery.

Postoperative period was uneventful in 29 cases. Seven patients developed surgical site infection and 5 patients had failed attempt at VVF repair.

\section{Discussion}

Although rare, the 41 urologic complications following gynaecological surgery represent $3.5 \%$ of all hospital 
Table 4. Distribution of the patients according to the nature of the treatment.

\begin{tabular}{ccc}
\hline Nature of treatment & Frequence & Pourcentage (\%) \\
\hline Repairs of VVF & 31 & 75.6 \\
Vesico-ureteral unilateral reimplantation & 4 & 9.8 \\
Removing of ureteral ligation & 3 & 7.3 \\
Vesico-ureteral bilateral reimplantation & 2 & 4.9 \\
End to end ureteral anastomosis & 1 & 2.4 \\
Total & 41 & 100 \\
\hline
\end{tabular}

admission in the service of urology during the study period of 5 years. Bouya et al. [1] have reported 3\% of urologic complications following gynaecological and obstetric surgeries over 9 years. 81 complications were reported in Congo [1] and 16 in Conakry [7] over there study period. The mean age of the patients in our study is 41 years. Tazi et al. [8] reported mean age of 40 years. This advanced age could be explained by the delay in presentation and also poor socioeconomic status of these patients, this has limits their access to healthcare. The difficult matrimonial status (divorced person, widow, either separated unmarried) was also a factor limiting in 48.8. This may be due to the lack of experience on the site of some of the operators [1] and lack of surgical skill [9]. In the academic hospitals, these complications were not negligible. Rajasekar et al. [10] discovered that these complications occurred as the obstetricians "junior" when the seniors were not around. This remark has been confirmed by the study of Tazi et al. [8], where in $90 \%$ of the cases a gynaecologist or an obstetrician information was responsible of the bladder injury. According to the literature, factors responsible for urinary tract injuries during gynaecological and obstetric surgeries includes previous abdominal surgeries, and gynaeco-obstetric (cicatricle uterus) as well as the presence of overhaul anatomical pelvic (irradiation, inflammation, big myoma) [11] [12].

In our study, caesarean section was the main reason of urologic complications in $53.7 \%$ of the patients which is similar to $50 \%$ reported by Bouya et al. [1]. VVF were the most frequent urologic complications following gynaecologic and obstetric surgeries in our study (64.5\%), this is also similar to report by Bouya et al. [1] in Congo with a rate of VVF reaching up to $67.9 \%$. The VVF were always the most frequent anatomical shapes [2] [13]. Hysterectomy is the second most common cause of VVF (57.9\%) in our study. On the other hand, some studies have show ureteral injuries to be the predominant urologic complication following hysterectomies [1]. This difference could be explained by the fact that it is difficult to ascertain if the fistula occurred before the hysterectomy.

The diagnoses of these injuries were made intraoperatively in only two cases $(4.9 \%)$ : an uretero-vaginal fistula and a bilateral ligation of the ureters. This shows that intraoperative diagnosis is rare as reported by Bentaleb et al. [9]. The remaining 39 cases were all diagnosed in the postoperative period. There is delay in referring these patients, with only $19.5 \%$ presenting within one year of diagnosis while $46.3 \%$ present after more than one year of diagnosis. The mean delay in diagnosis was 5 months for ureteral lesions in other studies [9]. The diagnosis of VVF was confirmed by methylene blue test while IVU was used to confirm ureteral injuries. Ultrasonography was contributory among the patients complaining about loin pains while CT urography has not been requested in these cases.

In our study, all the patients underwent open surgery, which is similar to report by Bouya et al. [1]. Other authors reported endoscopic intervention as the first line of treatment [13]. The low way has been privileged for treatment of the VVF by vesico-vaginal division. The ureteral injuries were treated by vesico ureteral reimplantation or end-to-end anastomosis. On the other hand, 3 patients benefitted from a simple removal of ligation. These techniques are used if ureteric ligation is discovered intra-operatively or during immediate postoperative period [9] and may require putting of a ureteral stent or a JJ stent after removal of the obstruction. The overall success rate in our study is $87.8 \%$. It is $100 \%$ for the ureteral injuries and $83.9 \%$ for VVF. Surgical site infection was seen in $17.1 \%$ of patient. These rates are comparable to those gotten by Bouya et al. in Congo [1]: $96 \%$ for the ureteral injuries and $90 \%$ for VVF.

\section{Conclusion}

Urologic complications following gynaecological and obstetric surgeries remain common even in CUUA of the 
CNHU of Cotonou. These iatrogenic injuries to the urinary tract occur more common during caesarean sections and trans-abdominal hysterectomies. Early diagnosis especially during surgery may help to avoid serious complications and need for second open surgery in the absence of endoscopic facilities. The treatment is mainly surgical and success rate is often good except for VVF which is associated with significant failure rate, depending on the operator. The most important preventive factor is good knowledge of the pelvic anatomy and sound surgical skill for caesarean section and trans-abdominal hysterectomy.

\section{References}

[1] Bouya, P.A., Odzébé, A.W.S., Otiobanda, F.G., et al. (2011) Les Complications urologiques de la chirurgie gynécologique. Progrès en Urologie, 21, 875-878. http://dx.doi.org/10.1016/i.purol.2011.03.008

[2] Zoung-Kanyi, J. and Sow, M. (1990) Le Point sur les fistules vésico-vaginales à l'hôpital central de Yaoundé: A propos de 111 cas observés en Dix ans. Urology Annals, 24, 457-641.

[3] Minar, L., Weinberger, V. and Kysela, P. (2010) Complications of Radical Onco-Gynecological Operations. Ceska Gynekologie, 75, 346-352.

[4] Symmonds, R.E. (1976) Ureteral Injuries Associated with Gynecologic Surgery: Prevention and Management. Clinical Obstetrics \& Gynecology, 19, 623-644. http://dx.doi.org/10.1097/00003081-197609000-00012

[5] Carley, M.E., McIntire, D., Carley, J.M. and Schaffer, J. (2002) Incidence, Risk Factors and Morbidity of Unintended Bladder or Ureter Injury during Hysterectomy. International Urogynecology Journal, 13, 18-21. http://dx.doi.org/10.1007/s001920200004

[6] Culty, T., Leret, T. and Botto, H. (2008) Lesions opératoires de l'urétère. EMC-18-160-A-10.

[7] Diallo, M.B., Diallo, A.T., Sow, K.B., et al. (2001) Les Complications urologiques de la chirurgie gynécologique. A propos de 16 cas. Annales d'Urologie, 35, 210-215. http://dx.doi.org/10.1016/S0003-4401(01)00034-1

[8] Tazi, M.F., Athalial, Y., Ahsaini, M., et al. (2010) Plaies vésicales d'origine gynéco-obstétricale à propos de 20 cas. Journal Marocain d'Urologie, 17, 17-21.

[9] Bentaleb, H., Bensouda, A., Kabbaj, M., Karimouni, T., Tazi, K., et al. (2007) Prise en charge des traumatismes iatrogène de l'uretère: A propos de 24 cas. African Journal of Urology, 13, 219-225.

[10] Rajasekar, D. and Hall, M. (1997) Urinary Tract Injuries during Obstetric Intervention. BJOG: An International Journal of Obstetrics \& Gynaecology, 104, 731-734. http://dx.doi.org/10.1111/j.1471-0528.1997.tb11986.x

[11] Blandy, J.P., Badenoch, D.F., Fowler, C.G., et al. (1991) Early Repair of Iatrogenic Injury to the Ureter or Bladder after Gynecological Surgery. Journal of Urology, 146, 761-765.

[12] Mattingly, R.F. and Thompson, J.D. (1985) Telinde's Operative Gynecology. 6th Edition, J.B. Lippincott \& Co., Philadelphia.

[13] Kamouni, T., Patard, J.J., Bensalah, K., et al. (2001) Prise en Charge urologique des traumatismes iatrogènes de l'uretère. Progrès en Urologie, 11, 642-646. 
Scientific Research Publishing (SCIRP) is one of the largest Open Access journal publishers. It is currently publishing more than 200 open access, online, peer-reviewed journals covering a wide range of academic disciplines. SCIRP serves the worldwide academic communities and contributes to the progress and application of science with its publication.

Other selected journals from SCIRP are listed as below. Submit your manuscript to us via either submit@scirp.org or Online Submission Portal.
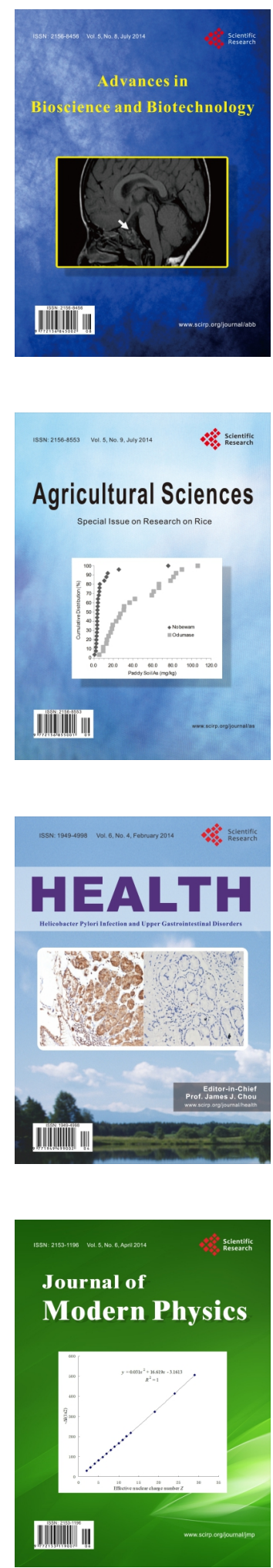
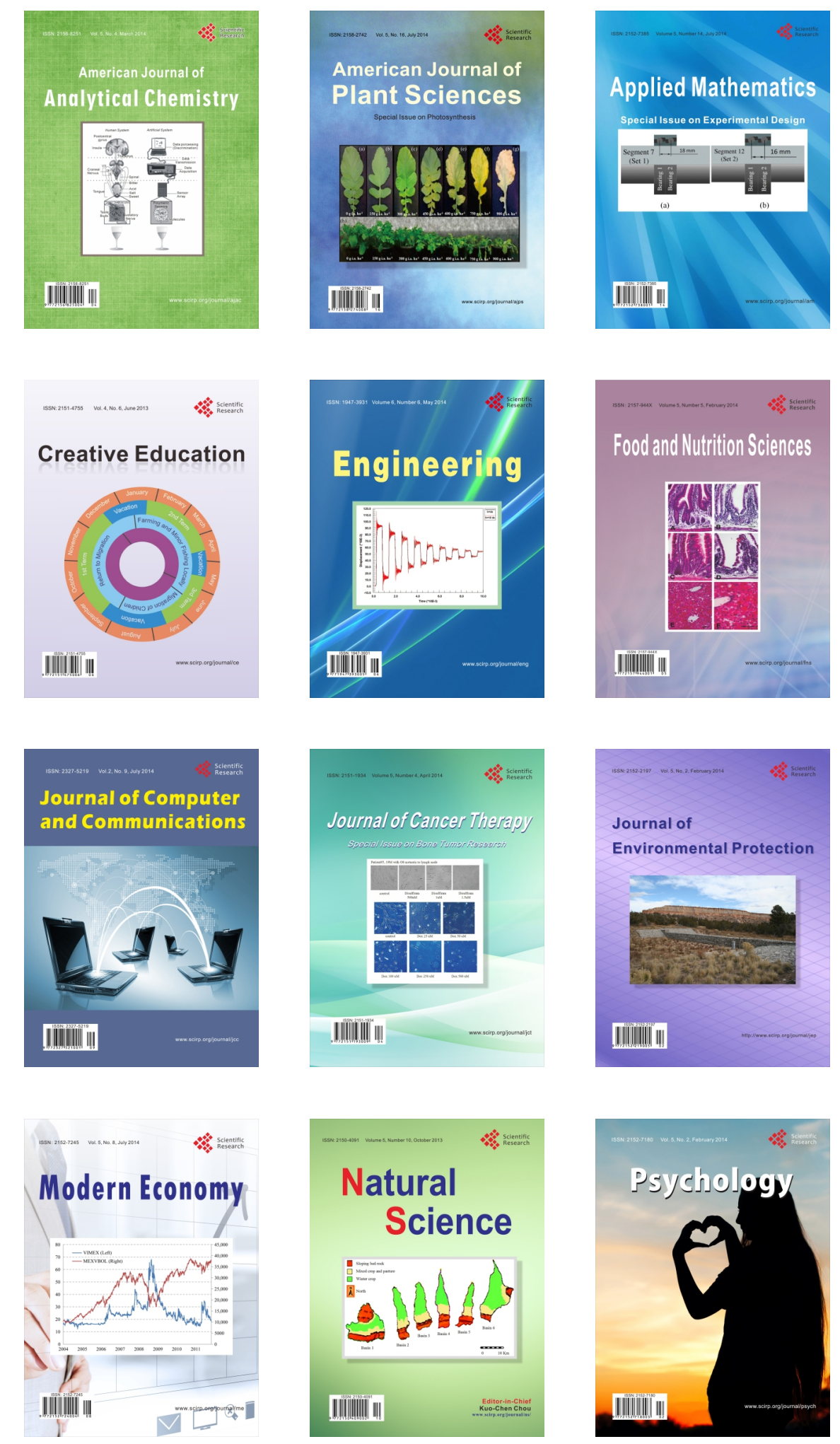